\title{
OS DISCURSOS E OS DILEMAS DA FORMAÇÃO ESTÉTICA ENTRE EMANCIPAÇÃO E BARBÁRIE
}

\author{
Márcia Torres Pereira \\ Universidade Federal de Goiás (UFG), Goiânia, Goiás, Brasil
}

\begin{abstract}
Resumo: O presente artigo objetiva uma discussão sobre as contribuições das narrativas verbais em prosa e não verbais na formação de sujeitos em seu sentido estético e propõe uma reflexão sobre os processos identificatórios e societários que sofrem interferências da indústria cultural, ancorada nos seguintes autores da teoria crítica da sociedade: Theodor Adorno (1903-1969) e Max Horkheimer (1895-1973). Considera-se a relação entre universal e particular, teoria e prática, forma e conteúdo, sujeito e objeto como procedimento metodológico da dialética negativa. Destacam-se neste texto os fenômenos que incidem sobre as (im)possibilidades de os sujeitos realizarem a experiência da reflexão no sentido de investigar e apresentar as condições que legitimam as narrativas com fins à emancipação e à barbárie.
\end{abstract}

PalAVRAS-ChAVE: Narrativas. Emancipação. Barbárie. Indústria cultural.

INTRODUÇÃO

O breve artigo faz referência a um cenário em processo com vistas ao diálogo e compõe o conjunto de estudos sobre as contribuições das narrativas verbais em prosa e não verbais na formação de sujeitos. Tem por propósito possibilitar ao leitor a experiência que, por razões heurísticas, perpassa pela reflexão sobre a formação à autonomia permeada por alguns processos identificatórios e societários instituídos pela racionalidade moderna e suas transformações, ancorada nos autores da teoria crítica da sociedade, Adorno 
e Horkheimer, considerando a relação entre universal e particular, teoria e prática, sujeito e objeto.

Embora Adorno (1995) tenha como fundamento a relação entre indivíduo e sociedade e seus estudos estejam voltados à emancipação dos sujeitos sociais e à experiência da reflexão, o referido autor comunica a crítica sobre a adaptação dos sujeitos aos conteúdos objetivos de uma realidade social reificada e destaca a necessidade de se fazer violência contra o pensamento identificador dessa mesma realidade. Isso significa uma forma de resistência contra a barbárie, com vistas a negar a conformação social sem reflexão.

Para Adorno e Horkheimer (1985), torna-se ponto basilar para a teoria crítica da sociedade concentrar-se na preocupação direcionada aos rumos da cultura e aos desafios à humanização na luta contra a violência e a barbárie, manifesta pela racionalidade técnica na sociedade administrada pela lógica econômica do consumo. A instrumentalização da cultura moderna atingiu a dimensão da consciência dos sujeitos, dificultando a realização da experiência. É resultado de uma época cujos discursos são engendrados pelo fenômeno da padronização como totalidade social, exigindo-se um pensamento idêntico ao que é instituído socialmente. A cultura, ao conceber indiferenciação em todos os modos de produzir a vida, diante das transformações existentes no mundo do trabalho, outros contornos emergem na atualidade da cultura instrumentalizada, consolidando ainda mais os processos de reificação dos sujeitos pela primazia da técnica.

No que tange ao tema proposto, as narrativas discursivas expressam a dimensão e a apreensão necessárias sobre as distintas determinações que a realidade histórico-social confere. Compreendidas como prática social, as narrativas discursivas distinguem-se entre verbais e não verbais. Para Fairclough (2016), a prática discursiva envolve processos de produção, distribuição e consumo textual, e a natureza desses processos varia em diferentes tipos de discursos, de acordo com os fatores e os contextos sociais específicos. Há implicações que se baseiam em aspectos filosóficos, políticos e culturais, numa perspectiva em que interações sociais se modificam e são modificadas pelo social e por suas representações.

Nesse sentido, na sociedade moderna, se os textos são consumidos em contextos sociais diversos, o consumo, assim como a produção, pode ser individual ou coletivo. Ambos têm intencionalidades socialmente hegemônicas em diferentes domínios institucionais da sociedade. As suas configurações tanto moldam os impulsos subjetivos como também fazem referência ao universo objetivo determinante. 
Segundo Compagnon (2010), no processo de produção dos textos, portanto, há dimensões sociocognitivas de produção e de interpretação textual centralizadas na inter-relação entre os recursos dos membros participantes autores, os quais trazem consigo memórias coletivas interiorizadas para a produção e a interpretação textual, dialogando com leitores que tornam-se leitores-autores. Esse processo, durante a elaboração dos textos, ocorre a partir de experiência internalizada, envolvendo a memória e a dinâmica da tradição histórica.

Nesse processo mencionado há, entretanto, uma eficácia ideológica consolidada por uma racionalidade moderna, na qual a crítica exige o real esclarecimento sobre a cultura, desvelando as contradições que permeiam a produção e a interpretação dos discursos presentes nas narrativas verbais e não verbais. É importante considerar que, para Adorno (2012), o conceito de "ideologia é inverdade, falsa consciência, mentira. Ela se manifesta no malogro das obras de arte, no que elas têm de falso em si mesmas, que deve ser apontado pela crítica" (p. 68).

Isso posto, problematiza-se a possibilidade de experiência estética à emancipação dos sujeitos pela relação dialética entre discurso e sociedade, à luz da teoria crítica da sociedade. Consideram-se nesse aspecto as narrativas como discursos, produzindo efeitos relacionais em discursos regulados pelas representações sociais como também de seu significado pragmático, restringindo as análises dos sujeitos.

Para Adorno (1985), embora os sujeitos tenham necessidades sociais e se constituam no exercício de suas funções a efetividade da manutenção, da produção e da reprodução social, eles são também capazes de realizar uma experiência crítica na sociedade da contradição, buscando as condições que correspondam à liberdade de pensamento como possibilidade de resistência à adaptação social determinada e unidimensional.

Pensar sobre as narrativas verbais e não verbais e suas implicações significa refletir sobre a contribuição que esses discursos podem oferecer à manutenção das condições universais instituídas, assim como sobre a exigência de sua crítica com fins à emancipação dos sujeitos. Para romper com as dificuldades que oferecem resistência à denúncia da ideologia que as afirmam, cabe investigar e apresentar as condições que legitimam as narrativas com fins ao conformismo e ao imediatismo das vivências fragmentadas, destituídas de reflexão e de autonomia, pois os conteúdos tendem a seguir a forma social universal, identificando-se com elas.

Diante do exposto, serão apresentados alguns aspectos históricos sobre as narrativas verbais em prosa desde a antiga Grécia, tendo como base 
a teoria crítica da sociedade moderna e fomentando a discussão que objetiva refletir posteriormente sobre as possibilidades de emancipação dos sujeitos $\mathrm{e}$ os mecanismos ideológicos que instituem a violência e as formas de barbárie presentes nos discursos narrativos.

\section{1 - AsPECTOS HISTÓRICOS SOBRE AS NARRATIVAS VERBAIS EM PROSA E A TEORIA CRÍTICA DA SOCIEDADE}

Contar histórias pode ser compreendido como a capacidade de recolher vivências, uma fonte que busca resgatar o passado, podendo se constituir como fenômeno cultural e, nessa medida, expressar um movimento dinâmico no contínuo das produções historicamente humanas. Tratam-se também de construções coletivas que, para D'Onofrio (2004), emergem da natureza humana para lidar com seus anseios e temores.

Pode-se, portanto, considerar que, desde os primórdios, há uma necessidade humana em buscar respostas, descobrir as possíveis verdades sobre os fenômenos, para se compreender a realidade. Foi a partir de narrativas mitológicas que essas possíveis respostas foram ocorrendo, mas graças à distância do desenvolvimento humano à história, à lógica e à arte, o homem consagra o fim da inocência mítica.

As narrativas expressaram inicialmente, desde a antiguidade na Grécia, um caráter de unicidade permanente em seu estágio primitivo, para justificar a origem das coisas e os comportamentos humanos, conforme tratou Aristóteles sobre o mito na tragédia. Essa narrativa é uma imitação da realidade, voltada sempre para consolidar ações próprias da vida em seu sentido estético.

Nesse processo, Aristóteles (2001), em sua obra Poética, chama a atenção sobre a forma de percepção da realidade em seu sentido estético e não do mundo empírico. Ou seja, em seu sentido voltado à superação, ao aprimoramento eà recriação do real, ao desenvolvimento global e harmonioso

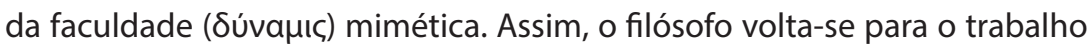

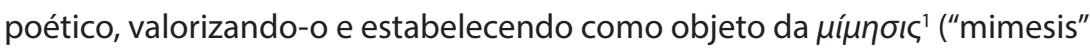
ou "mimese"), no processo narrativo, o conteúdo, que abarca a apreensão global de uma realidade formada por homens livres em seu sentido ético, conforme comparece em sua obra Ética a Nicômaco:"Toda ação humana está orientada para o bem e para a felicidade que se define como criatividade da alma dirigida pela virtude perfeita" (ARISTÓTELES, 2009, p. 13).

Ao considerar a formação estética como elemento significativo à emancipação do indivíduo, cabe ressaltar a importância inicial da educação 
para a adaptação e sua relação com a cultura, considerando os processos miméticos da formação da criança, os quais incidem sobre a imaginação. Como afirma Wulf (2013, p. 14), "a educação pode ser compreendida como um processo mimético no qual a crítica aos modelos também desempenha um papel importante".

A emergência da reflexão na formação do indivíduo moderno tem como base a troca como elemento determinante nas relações entre os homens, em que a aquisição mimética dos padrões culturais estabelecidos confere correspondência às imagens produzidas pela cultura como se fossem reais. Imitar significa copiar e, por isso, pode gerar competitividade, rivalidade e violência (WULF, 2013).

A reabilitação do termo mimese, que vai além de uma mera adaptação da realidade, se expressa na perspectiva da teoria crítica da sociedade, em especial em Adorno e Horkheimer (1985), como uma denúncia sobre a realidade moderna, em que o conceito de mimese se expressa como cópia, em relação à exigência da existência de uma adaptação forçada e violenta. Esta, por sua vez, oposta à autonomia, consagra-se para os sujeitos como ameaça de um sentimento de desamparo, ${ }^{2}$ cuja identidade à racionalidade é própria da dominação social.

Sob a égide dos ordenamentos de conformação ao programa da razão moderna, Adorno e Horkheimer (1985) afirmam que o esclarecimento

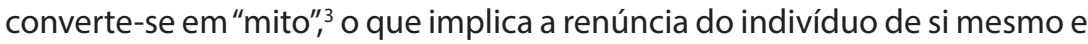
de sua maioridade em sentido kantiano - a autonomia. O caráter conformador é antecipado para abdicar do privilégio da experiência que envolve o trabalho e a reflexão, ou seja, consiste em abdicar da consciência que envolve o questionamento crítico de uma realidade que ameaça a si mesma, em função dos "esquemas arcaicos de autoconservação: a vida paga o tributo de sua sobrevivência, assimilando-se ao que é morto" (ADORNO; HORKHEIMER, 1985, p. 168).

Para Adorno (2009), a experiência da reflexão refere-se à formação de uma consciência esclarecida diante dos desdobramentos ocorridos, tanto objetiva quanto subjetivamente, que incidiram sobre a racionalidade moderna de ordem econômica, política, social e cultural. Essa experiência perpassa pela dialética negativa que, segundo Zanolla (2015), enfrenta desafios epistemológicos e filosóficos, buscando na tradição dos conhecimentos que sustentam a compreensão da dinâmica histórica e as contradições que envolvem o conceito, a sociedade e o indivíduo com vistas a desmistificar as determinações, considerando as relações dicotômicas, fetichizadas e ambivalentes dos conhecimentos e seus efeitos epistemológicos, práticos e teóricos. 
A experiência desmistificada pensada por Adorno (2009) exige o pensamento dialético para "pensar as contradições presentes, sobre a causa dessas contradições experimentadas na e contra a coisa, sendo contradição da realidade e contradição pela realidade" (p. 148). O universal não é uma substância própria, contraposta aos indivíduos, mas ainda assim é uma realidade coesa dotada de força e poder que não consiste simplesmente na soma dos indivíduos. Porém, é exatamente pela experiência do caráter contraditório da realidade social que se pode pensar em uma sociedade diferente da que existe, pois ela se torna um problema por meio daquilo que ela não é.

Nesse sentido, Adorno (2012) afirma que"o telos da narrativa é porém o diferente, e a identidade impiedosamente rígida que fixa o objeto épico serve justamente para alcançar sua própria diferenciação, sua não identidade com o meramente idêntico, com a monotonia não articulada" (p. 48).

Sobre a consciência crítica a respeito de uma ideologia literária, Compagnon (2010) refere-se aos efeitos exercidos pelas obras sobre os leitores, que contém fatores externos, tendo a história como contexto, para indagar aos críticos: "o que chama de literatura? Quais são seus critérios de valor? [...]" (p.22). Para essas questões, o autor referido afirma que os estudos literários são diversos e abarcam forma e conteúdo estéticos, produzindo historicamente seu lugar no século XIX como equivalente à cultura: "[...] os dois grandes gêneros, a narração e o drama, abandonavam cada vez mais o verso para adotar a prosa. [...] Desde então, por literatura compreendeu-se o romance, o teatro e a poesia, retomando-se à tríade pós-aristotélica dos gêneros épico, dramático e lírico [...] (COMPAGNON, 2010, p. 32).

Em Aristóteles (2011), na Poética, a epopeia tornou-se diferente da lírica e do drama (tragédia) por ser "a palavra narrada"e por unir a imaginação popular e os acontecimentos históricos com uma veste literária, a saber: a Ilíada, narrada por Homero sobre a guerra de Troia no século VII a. C., e a Odisseia, sobre o pós-guerra.

No poema épico o foco narrativo está centrado sobre um narrador onisciente, mas volta e meia aparecem outras focalizações evidenciadas pelas falas das personagens ou pela intervenção do eu poemático. [...] A narração épica, além de verter sobre um fato bélico grandioso, historicamente acontecido mas idealizado pela imaginação coletiva, criadora de mitos e lendas, está diretamente relacionada com o surgimento ou o progresso de uma nacionalidade (D'ONOFRIO, 2004, p. 115).

Ao tomar o discurso narrativo diante do passado histórico, a epopeia apresenta seu aspecto estético, político e uma linguagem descritiva para 
compensar a inverdade de todo o seu discurso. Nesse sentido, Adorno (2012) destaca a forma autônoma da obra, quando ela "rasga a trama da narrativa", possibilitando que a história se destaque em relação à narrativa, impulso que possivelmente levou Flaubert, ao considerar o momento histórico da realidade, a escrever seus romances na modernidade. Esse aspecto ressalta a importância de proximidade entre a epopeia e o romance, como gênero que expressa a realidade diferenciada daquela que se pretendia manipular.

Assim, com base no exposto, a linguagem "leva ao extremo sua vontade de determinação, de se curar da manipulação conceitual dos objetos, o negativo de sua intencionalidade, deixando aflorar a realidade de forma pura, não perturbada pela violência da ordem classificatória" (ADORNO, 2012, p. 51).

Ainda sobre o romance, Bakhtin (1998) afirma que o personagem não deve ser heroico no sentido épico, mas deve reunir em si traços positivos e negativos, inferiores e elevados. Além disso, o romance não deve ser considerado como algo acabado, mas dinâmico, crítico e autocrítico. Sendo um gênero em constante evolução, "o romance introduz uma problemática, um inacabamento semântico específico e o contato vivo com o inacabado, com a sua época que está se fazendo (o presente ainda não acabado)" (BAKHTIN, 1998, p. 400).

Embora o romance procurasse exercer o seu domínio estético pela experiência do desencantamento do mundo, transformando-o pelo discurso narrativo que expressa a possibilidade de reflexão sobre a realidade, esse gênero foi limitado pela própria linguagem discursiva, substituído na contemporaneidade pela reportagem, que tem presente em seus discursos a função comunicativa da linguagem e os mecanismos ideológicos somados à técnica da persuasão, reproduzindo a realidade correspondente aos intentos da indústria cultural. Assim, diante das condições do mundo moderno, os estudos e as pesquisas de Adorno e Horkheimer (1985) empreenderam esforços para compreender as razões que levaram os conhecimentos socialmente produzidos, assim como a cultura e o desenvolvimento tecnológico de forma geral, a não acompanhar o desenvolvimento verdadeiramente humano e autônomo.

Cabe refletir sobre os processos formativos do sujeito moderno, que se expressaram em suas manifestações de luta e resistência, os quais estiveram voltados à conquista de liberdade referente à capacidade do sujeito autodeterminar sua própria essência, a partir de seus atributos básicos de sua consciência emancipatória. A contradição que se apresenta para o sujeito do esclarecimento é, conforme apresenta Adorno e Horkheimer (1985), o da 
ordem inversa de seu sentido, qual seja a condição de objeto, pela qual se expressa o fundamento da racionalidade moderna.

Entrementes, a possibilidade de narrar é interditada pela racionalidade técnica, que avalizou a guerra para alcançar progresso. Isso significa que:

contar algo significa ter algo especial a dizer, e justamente isso é impedido pelo mundo administrado, pela estandartização e pela mesmice. Antes de qualquer mensagem de conteúdo ideológico já é ideológica a própria pretensão do narrador, como se o curso desse mundo ainda fosse essencialmente um processo de individuação, como se o indivíduo, com suas emoções e sentimentos, ainda fosse capaz de aproximar da fatalidade, como em seu íntimo ainda pudesse alcançar algo por si mesmo: a disseminada subliteratura biográfica é um produto da desagregação da própria forma de romance (ADORNO, 2012, p. 57).

Destacam-se os mecanismos utilizados para realizar, contraditoriamente, a inversão da emancipação em dominação, consoante o pensamento adorniano, segundo o qual qualquer forma social carrega também uma forma da dominação. Nesse processo em que as narrativas são expressões constitutivas das práticas sociais, Adorno e Horkheimer (1985) denunciam a lógica harmônica, os fenômenos históricos e os antagonismos reais presentes na base material, tomando a totalidade da práxis social para o exercício da crítica dialética.

Embora seja obstaculizada a possibilidade de emancipação, Adorno (2012) expressa que, na produção mais avançada,

[...] O sujeito literário, quando se declara livre das convenções de representação do objeto, reconhece ao mesmo tempo a própria impotência, a supremacia do mundo das coisas, que reaparece em meio ao monólogo. É assim que se prepara uma segunda linguagem, destilada de várias maneiras do refugo da primeira, uma linguagem de coisa, deterioradamente associativa, como a que entremeia o monólogo não apenas do romancista, mas também dos inúmeros alienados da linguagem primeira, que constituem a massa (ADORNO, 2012, p. 62).

Adorno (1903-1969) dedicou a vida ao entendimento dos processos de formação do homem em sociedade e, como um dos fundadores da Escola de Frankfurt, se dedicou a compreender a lógica da indústria cultural para denunciar seus mecanismos ideológicos e as contradições veladas, defendendo a necessidade de transformação da estrutura social. Assim, educação e cultura se comunicam nos estudos adornianos para as possibilidades da formação para a emancipação e o combate à manutenção da barbárie. 
A indústria cultural, termo cunhado em 1947 na obra Dialética do Esclarecimento, escrito em parceria com Max Horkheimer (1895-1973), referese a um fenômeno histórico originário da reestruturação do sistema capitalista, com fins à manutenção dos processos e mecanismos de instrumentalização ideológica de dominação cultural (JAY, 2008). Desse modo, os procedimentos da indústria cultural interferem na realização de experiências formativas, autocríticas e criativas, atingem a dimensão da consciência social e se constituem como um expressivo desafio à humanidade, na luta contra a violência e a barbárie manifestas pela primazia da técnica.

Em uma sociedade informatizada pela disseminação do que precisa ser visto, ouvido e acreditado, corrobora o fato de que milhões de pessoas participam dessa indústria sem a reflexão necessária, pois a manipulação consiste em induzir os indivíduos a seguir seus ordenamentos, os quais foram baseados nas demandas latentes da massa. Assim, visando realizar apenas o resultado obtido pela ação dos outros indivíduos de forma padronizada, a indústria cultural determina as escolhas sem que as pessoas necessitem refletir sobre elas, como se usurpasse o esquematismo em sentido kantiano, domesticando também os momentos de criação pela determinação de estilos. Essas considerações remetem ao pensamento de Aristóteles na sua obra Política que, longe de opor-se à theoría a práksis, esta última é a própria theoría, pois a vida prática tem o fim em si própria e exercita-se por si mesma.

Devido à imediticidade da vida moderna, impõem-se métodos de reprodução que, por sua vez, "tornam inevitável a disseminação de bens padronizados para a satisfação de necessidades iguais. [...]. Os padrões teriam resultado originariamente das necessidades dos consumidores: eis porque são aceitos sem resistência" (ADORNO; HORKHEIMER, 1985, p. 100).

\section{2 - O SENTIDO ESTÉTICO DAS NARRATIVAS NÃO VERBAIS E A INDÚSTRIA CULTURAL}

A modernidade, fundada na crença na razão, no progresso e no poder emancipatório da ciência, mudou a visão de mundo, a qual se expande até a fase do capitalismo que, ao ganhar vulto, tornou-se alvo de questionamentos sobre as possibilidades e impossibilidades de sua efetivação em favor da emancipação dos sujeitos. Devido à concentração de produção e à lucratividade concedidas pela modernização, surge um aparato tecnológico que objetiva dimensionar a organização social do trabalho via integração ideológica entre as distintas instituições. A ética (éthos), uma vez modificado o seu sentido, é produzida por processos sociais globais identificados com a tecnologia interativa e seus discursos culturais persuasivos para uma sociedade cada vez mais integrada. Esse processo de integração ideológica, 
apresentado por Adorno e Horkheimer (1985), diz respeito às ideias e também à materialidade sob o domínio da técnica, que incide sobre valores, comportamentos, linguagem e narrativas verbais e não verbais, abarcando essas características e esses modos de organizar a vida que a indústria cultural se encarrega de produzir.

Desprovida de seu sentido, a cultura moderna, reduzida ao seu pequeno reduto do entretenimento, iniciado no século XIX a partir do rádio e do cinema, e ligada aos interesses dos especialistas, funda-se na produção de uma aparelhagem ordenadora, na qual tudo pode ser utilizado como meio de "cultura". Seus dimensionamentos, ao longo do século XX, alcançaram manifestações globais de forma ideológica, em que mensagens sofisticadas capturam necessidades e demandas latentes dos sujeitos, as quais se manifestam nas narrativas verbais e não verbais com fins à sua manutenção.

O lugar do conhecimento e da formação estética não é mais sua finalidade, pois esta passa a ser apenas um meio que reserva um lugar do prazer imediato, produzindo a adaptação. Nesse "território cultural", há um encolhimento da dimensão estética que, transfigurada em imagem, corresponde aos intentos de uma realidade demasiadamente autoritária (ADORNO, 2012). Assim, encontrando oposição para a emancipação dos sujeitos e os conteúdos para avaliar a razão instrumental, que tem como base o discurso da identificação que foi concebido pela linguagem, resta o compromisso com o conformismo:

"tu deves submeter-te", mas sem indicar a quê - submeter-se aquilo que de qualquer forma é o aquilo que, como reflexo do seu poder e onipresença, todos, de resto, pensam. Através da ideologia da indústria cultural, o conformismo substitui a consciência: jamais a ordem por ela transmitida é confrontada com o que ela pretende ser ou com os reais interesses dos homens [...] (ADORNO; HORKHEIMER, 1985, p. 99).

A degradação da identidade pela experiência afetada pela ausência de reflexão evidencia-se em mera vivência e faz pensar sobre o quanto as diretrizes da produção e da reprodução da vida na sociedade capitalista obstaculizam a autonomia e a consciência dos indivíduos. Embora evidencie uma racionalidade técnica no decurso da história moderna e contemporânea, que oriente os processos de formação humana para conduzir os homens à "invisibilidade", contraditoriamente a imagem na cultura moderna exerce poder devido à sua potência sobre a imaginação (Einbildungskraft), o fazer humano e seu quotidiano. Cabe à estética, nesse sentido, promover percepções sensíveis, o despertar de sensações, como também a formação humana para a autonomia, propondo 
uma educação para a reflexão e a busca pelo conhecimento capaz de oportunizar o movimento do pensamento dialético proposto por Adorno (2009), que abarque a ética e a política na condução de outras formas de conhecimento, como os científicos, os filosóficos e os artísticos.

Devido às formas universalizadas impostas, é determinante a condição de que, quanto mais houver a cópia, menos pensamento, percepção e sensibilidade, posto que "a visibilidade está no centro do processo de produção, que se tornou, em grande parte, de consumo, a ponto de [...] a visibilidade de si, atualmente, ser imposta ao indivíduo" (HAROCHE; ALBERT, 2013, p. 93).

Cindido de sua própria condição para a autonomia do pensamento, o sujeito se justifica na utopia de que o belo ideal é inalcançável ao homem. Essa "servidão voluntária" substituiu o objetivo iluminista de dominar a natureza para, através de sua própria criação - a técnica -, negar tudo o que é próprio da vida, tornando-a invisível. Assim, os modos de produção da vida em sociedade se constituem por um processo de fragmentação contínua, fazendo parte das formas de individualismo contemporâneo, conforme cita Haroche e Aubert (2013, p. 103), ocasionando a perda de sua identidade diante dos processos societários, referentes às mudanças sociais, os vínculos que os originaram e suas conexões com os processos econômicos, políticos, culturais e educacionais, os quais exigem que o sujeito seja:

Hoje consumidor, mas antes de mais nada objeto de consumo, consumido, consumindo, o indivíduo deve se vender e se consumir constantemente, e assim exigir nas telas, nas tecnologias contemporâneas, mostrar-se, exibir-se de forma reiterada; ele se encontraria diante de uma iniciação contínua que põe em xeque a capacidade de vontade, de escolha, de reflexão, a capacidade psíquica de atividade no consumo, levando em última análise à passividade e à submissão, até mesmo a supressão de si (HAROCHE; AUBERT, 2013, p. 103).

De acordo com a citação supracitada, poder-se-ia pensar em uma proximidade com o pensamento de Adorno (2009), em relação à visibilidade, considerando a emancipação como mote da discussão, que consiste em romper com a fixidez do pensamento aos determinantes da indústria cultural, enfocando a importância de se elaborar o passado como forma de conhecer as causas que permitiram o sofrimento humano. Nesse aspecto, cumprese o sentido da obra de arte na filosofia adorniana: "[...] que seria da arte enquanto historiografia, se ela se desembaraçasse da memória do sofrimento acumulado?" (ADORNO, 1970, p. 291).

Retirar o "véu da invisibilidade" sobre as causas que permitiram que a formação dos homens se mantivesse sob o jugo da dominação social, por 
parte da racionalidade daquilo que não era racional, impedindo a autonomia, consiste em eliminar essa repetição e conceber a educação para a adaptação da realidade em que a permanência das causas se expressa nessa condição invisível.

Em Adorno (1970), caberia à estética sustentar novos modos de formalização e ordenações que não fossem mais assentados na repressão da experiência de não identidade, mas pensar na promessa de uma nova ordem trazida pelo setor mais avançado da produção artística. $\mathrm{O}$ autor assumiu como necessário o fato de parar de ver a arte como a simples indicação de uma estética e assumi-la como setor privilegiado da história da razão. E mais: derivar todas as consequências do fato de uma certa experiência estética, com seus protocolos e formalizações, fornecer o modelo de reorientação das categorias da dialética para pensar em conjunto, por exemplo, a categoria de sujeito.

A crítica de Adorno (1970) denuncia a obra de arte funcionalizada, ou seja, como mercadoria que "faz parte daquela parcela da dialética da Aufklärung, em que processo e regressão são idênticos"(Adorno, 1970, p. 100). A arte perde, portanto, a sua aura, aquele distanciamento que transcende a história, ou seja, que a distingue dos mecanismos de dominação e produtos massificadores da indústria cultural. Assim, a cultura moderna encontrase em estreita relação com a produção de mercadorias, as quais, devido à mundialização do capital econômico, tornam possível comercializar bens simbólicos em detrimento da subjetividade. O desenvolvimento tecnológico cooptou a arte para servir à produção que visa a sua manutenção, sob a primazia da eficácia dos meios, que se sobrepõe à racionalidade dos fins e às esferas da subjetividade.

Adorno e Horkheimer (1985), ao denunciarem o caráter mercantil a que a arte é submetida, reclamam sua inversão para fazer valer a liberdade e a autenticidade da arte como oposto do produto da indústria. A arte, em permanente relação com o contexto social em seu duplo caráter, ora se manifestando como elemento distinto da realidade empírica, sem produzir efeitos sociais, ora como fenômeno estético, manifestando seu efeito social, não se realiza concretamente, pois só poderia fazê-lo na medida em que se constitui como autônoma.

Tal perspectiva crítica da sociedade pelo viés da cultura, entendida como espaço privilegiado das manifestações simbólicas e que constitui o sujeito, é o que esses autores se põem a reivindicar. Sua autenticidade ocorre, entretanto, quando a arte se alia à tarefa premente de preservar a percepção e os sentidos, prenunciando o sentir sobre o que não é dito de forma explícita, 
na perspectiva que abarca o racional e o sensível, encontrando ecos em outras formas de perceber o mundo sob a perda do esquematismo kantiano.

Ao analisar o cinema, assim como outras formas de narrativas não verbais, entendem-se suas dinâmicas como formas socialmente constituídas, devido a seu caráter cultural ambivalente, ora como instrumentos ideológicos como se fossem manifestações oriundas da massa, ora como potencial educacional. Consequentemente, novas relações com a obra de arte são manifestadas, inclusive seu sentido e seu significado. Em virtude desses fatores, a relação entre arte, trabalho e cultura na modernidade visa à educação estética como possibilidade emancipatória para proporcionar experiências que possibilitem a espontaneidade da formação de uma consciência das percepções.

Compreender as transformações de mundo em que o sujeito é afetado pelas forças produtivas e pelas relações de produção no continuum da história implica compreender que o humano como natureza e como cultura se modifica. Wulf (2013) contribuiu nesse sentido, ao conferir à imaginação (Einbildungskraft) um movimento dialético de relações e de representações: uma potência que faz o mundo aparecer ao homem, no sentido grego de phainestai (p. 22). Assim, a justaposição das imagens em nossa percepção, consequência do poder da imaginação, permite descontinuidade de movimento e, no interior do indivíduo, se apresenta decodificada. Semelhantemente ao que esse movimento pode ser para o cinema, é através dele que o mundo visível se manifesta como recriação exteriorizada em prol da intenção emancipatória.

Entrementes, em Adorno (1985), devido à indústria cultural, que fornece sua ideologia para a manutenção da realidade social capitalista, "o cinema integra várias camadas de modelos de respostas comportamentais [...] segundo os modelos que oficialmente visa" (p. 184). Não obstante, contrariando aos modelos que definem intencionalidades contrárias à formação para a emancipação, a estética do filme deveria recorrer à de experiência subjetiva, a uma narrativa que promovesse a experiência interior, a reflexão contemplativa.

Para tanto, cabe considerar a filosofia no mote dessa discussão, entendida como um "despertar, [...] um momento de ruptura refletido no pensamento", conforme cita Badiou (2015, p.36) ao dissertar sobre o cinema como experiência filosófica, que ocorre por uma relação paradoxal entre polaridades que possibilitam, entre outras, explorar as fronteiras da arte para criar sínteses. Ou seja, "a filosofia, ao pensar a ruptura, a escolha, a distância, a exceção ou a eventualidade do acontecimento, inventa uma nova síntese" (BADIOU, 2015, p. 42). 
É importante destacar que a leitura de Adorno citado por Caires et al. (2017) nos faz entender que: "existe algo que constitui sistematicamente no interior do discurso filosófico e que torna impossível a existência de respostas definitivas [...] A filosofia, ao invés disso, é o esforço de articulação conceitual, de modo a tornar perceptíveis os modelos de racionalidade que ordenam a realidade e seu movimento".

Quando Adorno (2009) sugere a emergência de uma nova racionalidade, na qual intuição e conceituação não se abdicam, ele propõe uma racionalidade que se oponha à indústria cultural, para não tolher a sensibilidade e o entendimento. A matriz tecnológica já possibilita que os sujeitos se vejam sob um realismo específico produzido pelos meios tecnológicos, pela difusão e pelo acesso dos recursos e produtos da indústria cultural, que se segmentam, se expandem e se redimensionam ao longo da história.

Nesse sentido, segundo Aumont et al. (2012), o cinema, ao ser reconhecido como arte entre os séculos XIX e XX, teve um empenho em desenvolver suas capacidades de narração, possibilitando uma experiência estética e conferindo aos sentidos uma dimensão de conhecimento e, ao nosso entendimento, a dimensão de sensibilidade.

Sobre a compreensão de o cinema ser compreendido como obra de arte, Badiou (2015) afirma que o cinema é o que guarda outras artes como a ideia da beleza do mundo sensível, a música enquanto dialética do visível e do audível, a narrativa do romance como forma de relato e a aura que conserva o ator do teatro.

Embora os mecanismos de dominação utilizem-se dos sentidos, das artes e dos conhecimentos produzidos para suas realizações, o "fermento orgânico" do cinema como arte emancipada se destaca, pois, nesse processo entre a ficção e a realidade, há uma consciência da relação arbitrária que o trabalho artístico estabelece com a realidade, ainda que haja a intenção de transpô-la rigorosamente. “O filme seria arte enquanto reposição objetivadora dessa espécie de experiência" (ADORNO, 1994, p. 102).

No que concerne ao desenvolvimento fílmico, Aumont et al. (2015) referem-se à forma como a narrativa é elaborada no espírito do espectador, ao afirmarem que, após a leitura não verbal (a visão do filme), é possível reconstruí-la. Por isso, para pensar numa educação estética a partir do cinema, o espectador deve sentir a necessidade da reflexão, diante das interpretações subjetivistas determinadas pela realidade deliberada, tendo a possibilidade de realizar o esforço intelectual, conhecendo os meios fetichizados que impedem a autonomia. Dessa forma, afasta-se do caráter coletivo a priori para 
se pôr a serviço da intenção emancipatória, a fim de chegar à coisa mesma. Ou seja, deve permitir-se pensar e fantasiar, livre do controle da identificação imediata com a realidade.

Essa preocupação referente aos aspectos subjetivos na compreensão da realidade advém das condições alienantes produzidas na e pela sociedade que, segundo Adorno (1995), apresentam-se como desafio ao intento de uma identidade não integrada à realidade. Diante de uma indústria cultural cujas ações são efetivas em seus mecanismos de dominação ideológicos sobre as relações de produção, envolvendo necessidades, desejos, emoções e crenças, a conscientização da educação estética à emancipação exige compreender a aparência de individualidade, a objetificação da subjetividade como elemento ideológico, ou seja, uma falsa práxis, em que os sujeitos confundam experiência com realidade, identificando-se com ela.

À guisa de considerações finais, a experiência estética se concretiza no desafio entre subjetividade e objetividade, um desafio capaz de produzir o que tem de artístico no sentido da formação para a emancipação. Em outras palavras, é significativo à formação estética que haja visibilidade histórica das contradições e não uma projeção do real, ou seja, a subsunção dos sujeitos diante das narrativas verbais, narrativas não verbais e a arte. "Experiência seria justamente a unidade entre tradição e anseio pelo desconhecido. Mas a própria possibilidade da experiência está ameaçada" (ADORNO, 2012, p. 91).

Contra a coerção da práxis dominante, a experiência estética visa à liberdade e ao distanciamento da mera existência, que se exprime em negativo nas narrativas que se constituem inteiramente segundo suas próprias leis. Assim, em oposição à situação social, apresenta as possibilidades que enunciam as possibilidades do diferenciado.

Não obstante as funções tradicionais do romance tenham se perdido diante das exigências da sociedade administrada pela lógica do consumo, Adorno (2012) adverte que "se o romance quiser permanecer fiel à sua herança realista e dizer como realmente as coisas são, então ele precisa renunciar a um realismo que, na medida em que reproduz a fachada, apenas a auxilia na produção do engodo"(p.57).

No caso do cinema, a instância narrativa deve ser propositalmente evidenciada em meio aos personagens, trata-se de uma história sendo contada ao público. O filme em seu caráter artístico, que promove a educação estética para a emancipação, não apresenta o mundo fictício que garante a imersão do público na história, antes relaciona elementos clássicos e ilusionistas sem o aparato tecnológico capaz de impedir que o público possa imaginar, sentir e refletir. 
A educação estética versa, portanto, sobre a conscientização do distanciamento entre sujeito e objeto, o que não impede o sujeito de sentir e refletir sobre a obra de arte, é, portanto elaboração, exercício de conhecimento da verdade ou do que aparece como verdade. É pela forma aberta da arte que é possível verificar que as narrativas verbais e não verbais podem proporcionar o distanciamento necessário para o exercício do pensamento crítico e a experiência da reflexão pensada por Adorno (2009), sem que o universal da realidade social venha a exercer o seu domínio sobre o particular para, então, consolidar a negatividade da formação à mera identificação com a realidade, resistindo-se, assim, à barbárie.

Artigo recebido em: 30/04/2018

Aprovado para publicação em: 25/06/2018

\section{NARRATIVE DISCOURSES ANDTHE DILEMMAS OF AESTHETIC FORMATION BETWEEN EMANCIPATION AND BARBARISM}

ABSTRACT:This article aims at discussing the contributions of verbal prose and nonverbal narratives in the formation of subjects in their aesthetic sense and is based on the reflection on the identification and societal processes that are interfered by the cultural industry, anchored in the following authors Theodor Adorno [1903-1969] and Max Horkheimer (1895-1973) of the Critical Theory of the Society, considering a relation between universal and particular, theory and practice, form and content, subject and object, as the methodological procedure of the negative dialectic. It highlights in this text the phenomena that affect the (im) possibilities of the subjects to realize the experience of the reflection in order to investigate and present the conditions that legitimize the narratives for the purpose of emancipation and barbarism.

KEYWORDs: Narratives. Emancipation. Barbarism. Cultural industry.

\section{LOS DISCURSOS NARRATIVOS Y LOS DILEMAS DE LA FORMACIÓN ESTÉTICA ENTRE EMANCIPACIÓN Y BARBARIE}

RESUMEN: Este artículo tiene el objetivo de discutir las contribuciones de las narraciones verbales, en prosa, y no verbales en la formación de sujetos, en su sentido estético, y pasa por la reflexión sobre los procesos identificatorios y societarios que sufren interferencias de la industria cultural. Se basa en autores de la teoría crítica de la sociedad, como Theodor Adorno [1903-1969] y Max Horkheimer [1895-1973]. Y, analiza la relación entre universal y particular, teoría y práctica, forma y contenido y 
sujeto y objeto, como procedimiento metodológico de la dialéctica negativa. En este texto, se destacan los fenómenos que recaen sobre las (im)posibilidades enfrentadas por los sujetos para realizar la experiencia de la reflexión, en el sentido de investigar y presentar las condiciones que legitiman las narrativas con fines a la emancipación y a la barbarie.

PALABRAS clave: Narrativas; Emancipación; Barbarie; Industria cultural.

\section{NOTAS}

1 É um conceito estético basilar, já que todas as artes às quais se refere as imitativas ou miméticas, ou seja, são baseadas num modelo que representam, que retratam. É o caso das várias formas de poesia e, numa palavra, de todas as artes que chamamos plásticas, como a escultura e a pintura (ARISTÓTELES, Poética, São Paulo: Edipro, 2011, p. 41).

2 Desamparo (hilflosigkeit). A evolução teórica de Freud diante da questão do desamparo parece ir no sentido de desacidentá-lo em relação ao evento traumático, de colocá-lo para além de uma simples regressão a uma fase em que o pequeno ser humano encontra-se completamente incapaz de sobreviver por seus próprios meios, de encontrá-lo, além de encontrar as figuras aterrorizantes do superego, para conferir-lhe um estatuto de dimensão fundamental da vida psíquica que indica os limites e as condições de possibilidade do próprio processo de simbolização.

30 mito converte-se em esclarecimento, e a natureza em mera objetividade. O preço que os homens pagam pelo aumento do seu poder é a alienação daquilo sobre o que exercem o poder. "O esclarecimento comporta-se com as coisas como o ditador se comporta com os homens. Ele conhece-o na medida em que pode manipulá-los" (ADORNO; HORKHEIMER, 1985, p. 24).

4 Kant entendeu por Esquematismo o "comportamento intelectual por esquemas" (Crítica da Razão Pura. Análise dos princípios. Cap. I).

5 "A vida prática, porém, não se refere propriamente aos outros indivíduos, como por vezes se julga, nem é forçosamente prático o pensamento que visa unicamente o resultado obtido pela acção. São muito mais práticas a contemplação e a meditação, pois têm o fim em si próprias e exercitam-se por si próprias" (ARISTÓTELES, 1998, VII, 1325b 17-21).

6 “[...] ideologia' significa sociedade enquanto aparência. Embora seja mediada pela totalidade, atrás da qual se esconde a dominação do parcial, a ideologia não é redutível pura e simplesmente a um interesse parcial; por isso, de certo modo, está em todas as suas partes à mesma distância do centro" (ADORNO, 1998, p.21).

7 Termo utilizado por Claudine Haroche e Nicole Aubert (2013), para referir-se ao estatuto contemporâneo da invisibilidade, que "diz respeito aos indivíduos quanto às 
instituições, aos organismos, às empresas. Este estatuto da invisibilidade aparece como uma tendência carregada, pouco discernível à primeira vista, que é profundamente reveladora de formas inéditas de inexistência para as instituições, de destituição, de privação de si para os indivíduos" (p.86).

8 A expressão "servidão voluntária" é encontrada na obra Discurso da servidão voluntária, de Étienne de La Boétie, e distingue-se da temática abordada pela autora deste estudo teórico e bibliográfico.

9 Termo compreendido como "trama peculiar de espaço e tempo: aparência única de uma distância, por muito perto que se possa estar" (p. 127). A "perda da aura" é a perda da excepcionalidade da obra de arte provocada principalmente pela fotografia e pelo cinema (BENJAMIN, 1992).

10 O termo "fantasia" está relacionado ao grego phainestais, no qual a ênfase principal recai sobre algo aparecendo ou sendo feito para aparecer. Em contraste, a ênfase no termo latino imaginatio está no processo de incorporar imagens, também acentuado no termo alemão Einbildungskraft (WULF, 2013, p. 22).

\section{REFERÊNCIAS}

ADORNO, T.; HORKHEIMER, M. Dialética do Esclarecimento: fragmentos filosóficos. Tradução de Guido A. de Almeida. Rio de Janeiro: Jorge Zahar Editor, 1985.

ADORNO, T. W. Teoria estética. Lisboa: Edições 70 Ltda., 1970.

. Notas sobre o filme. In: COHN, G. (Org.). Theodor W. Adorno: Sociologia. São Paulo: Ática, 1994. p. 100-107.

. Educação e emancipação. Rio de Janeiro: Paz e Terra, 1995.

. Dialética negativa. Tradução de Marco Antônio Casanova. Rio de Janeiro: Jorge Zahar Editor, 2009.

. Notas de literatura I. Tradução de Jorge M. B. de Almeida. São Paulo: Duas cidades; Editora 34, 2012. p. 47- 65.

ARISTÓTELES. Política. Ed. bilíngue grego-português. Tradução e notas de Antônio Campelo Amaral e Carlos de Carvalho Gomes. Lisboa: Vega, 1998.

Ética a Nicômaco. Tradução e notas de Antônio Castro Caeiro. São Paulo: Atlas, 2009.

. Poética. Tradução, textos complementares e notas de Edson Bini. São Paulo: Edipro, 2011.

AUMONT, J. et al. A estética do filme. Campinas, SP: Papirus, 2012.

BADIOU, A. O cinema como experimentação filosófica. In: YOEL, G. (Org.). Pensar o cinema: imagem, ética e filosofia. São Paulo: Cosac Naify, 2015. 
BAKHTIN, M. Epos e romance: sobre a metodologia do estudo do romance In: Questões de literatura e de estética: a teoria do romance. Tradução de Aurora Bernadini. 4 ed. São Paulo: UNESP; Hucitec, 1998. p. 397-428.

BENJAMIN, W. Sobre arte, técnica, linguagem e política. Lisboa: Relógio D’Água, 1992.

CAIRES, F. et al. Anotações contemporâneas em teoria crítica. Porto Alegre.: Editora Fi, 2017.

COMPAGNON, A. O demônio da teoria: literatura e senso comum. Belo Horizonte: Editora UFMG, 2010.

D'ONOFRIO, S. Formas de narrativa. In: . Teoria do texto 1. São Paulo: Editora Ática, 2004. p.105-126.

FAIRCLOUGH, N. Discurso e mudança social. Brasília: Editora Universidade de Brasília, 2016.

HAROCHE, C.; AUBERT, N. (Org.) Tiranias da visibilidade. São Paulo: Editora Fap/UNIFESP, 2013. p. 85-123.

JAY, M. A imaginação dialética: história da Escola de Frankfurt e do Instituto de Pesquisas Sociais [1923-1950]. Tradução de Vera Ribeiro. Rio de Janeiro: Contraponto, 2008.

KANT, I. Crítica da razão pura. Tradução de Fernando Costa Mattos. São Paulo: Vozes, 2012.

WULF, C. Homo Pictor: imaginação, ritual e aprendizado mimético no mundo globalizado. Tradução de Vinicius Spricigo. São Paulo: Hedra, 2013.

ZANOLLA, S. Dialética negativa e materialismo dialético: da subjetividade decomposta à objetividade pervertida. Kriterion, Belo Horizonte, n. 132, p. 451-471, dez. 2015.

MÁrcia Torres Pereira: Doutoranda em educação e Mestre em Educação pelo Programa de Pós-Graduação da Universidade Federal de Goiás, linha de pesquisa Cultura e Processos Educacionais, com ênfase na abordagem teórico-crítica da Escola de Frankfurt. Pesquisadora do diretório de pesquisa Teoria Crítica, Cultura e Educação da Universidade Federal de Goiás. Membro de pesquisa do Núcleo de Estudos em Educação, Violência, Infância, Diversidade e Arte (NEVIDA). Coordenadora interna do NEVIDA na linha de Teoria Crítica Frankfurtiana. Servidora pública, compõe o corpo docente da unidade CEPAE-UFG, em regime de dedicação exclusiva.

E-mail:marciaftorresp@gmail.com 